\begin{tabular}{|l|l|l|l|l|l|} 
J. Tek. Ling & Vol.11 & No.3 & Hal. 381 - 387 & Jakarta, September 2010 & ISSN 1441-318X \\
\hline
\end{tabular}

\title{
PENGARUH KOMPOSISI BIODIESEL TERHADAP KINERJA MESIN DAN EMISI GAS BUANG
}

\author{
Martin Djamin ${ }^{1}$ dan Soni S.Wirawan ${ }^{2}$ \\ Peneliti di Pusat Pengkajian dan Penerpan Teknologi Konversi dan Konservasi Energi' ${ }^{1}$ \\ Peneliti di Balai Rekayasa Desain dan Sistem Teknologi² \\ Badan Pengkajian dan Penerpan Teknologi
}

\begin{abstract}
Renewable energy sources make a distinction as a promising solution towards sustainable and environmentally friendly energy production. Developing biodiesel is very important for Indonesia due to various reasons including the abundance availability of the raw materials; an alternative renewable fuel to strengthen the country energy security and it is a solution to improve local air quality in several Indonesian major cities. Biodiesel offers a realistic short-term alternative to substitute fossil fuels, and it will also be a necessary addition to the emission free technology for the future. This paper is intended to provide assessment and investigation of the use of different composition of biodiesel and its impact to the environment.
\end{abstract}

Key words: Energy security, renewable energy, Biodiesel.

\section{PENDAHULUAN}

Setiap jenis kendaraan bermotor mempunyai faktor emisi yang spesifik. Faktor emisi tersebut tergantung dari teknologi dan kapasitas mesin serta jenis bahan bakar yang dipakai. Sampai saat ini hampir semua data faktor emisi didapat berdasarkan pengukuran kendaraan yang berbasis bahan bakar fosil (solar dan bensin), sedangkan data yang berbasis bahan bakar biodiesel masih sangat terbatas.

Biodiesel adalah bahan bakar terbarukan ramah lingkungan, yang terbuat dari minyak nabati. Secara kimia biodiesel termasuk dalam golongan mono alkyl ester atau metyl ester dengan panjang rantai karbon antara 12 sampai 20, sedangkan petroleum diesel (solar) mempunyai komponen utama adalah hidrokarbon. Karena mempunyai sifat kimia dan fisika yang serupa dengan solar maka biodiesel dapat digunakan langsung untuk mesin diesel atau dicampur dengan solar tanpa perlu memodifikasi mesin.

Biodiesel mempunyai flash point lebih tinggi dari pada solar, sehingga tidak mudah terbakar. Disamping itu biodiesel tidak mengandung sulfur ${ }^{1]}$ dan senyawa benzene yang karsinogenik sehingga biodiesel merupakan bahan bakar yang lebih bersih dan lebih mudah ditangani dibandingkan dengan solar. Sifat lain dari biodiesel adalah mempunyai Cetane number dan Viskositas lebih tinggi, serta sifat pelumasan yang lebih baik dibandingkan solar.

Makalah ini akan membahas kinerja mesin diesel dan pengaruhnya terhadap lingkungan (emisi gas buang) dengan 
menggunakan berbagai komposisi campuran biodiesel.

Campuran biodiesel yang akan dipergunakan pada penelitian ini adalah $\mathrm{B} 0$ (minyak diesel murni), B10, B20, B30, B50 dan B100 (biodiesel murni).

Kinerja mesin akan dievaluasi dengan pengukuran torsi daya dan konsumsi bahan bakar. Sedangkan evaluasi terhadap emisi dilakukan dengan pengukuran karbon monoksida (CO), hydrocarbon ( $\mathrm{HC}$ ), partikel $(\mathrm{PM})$, karbon dioksida $\left(\mathrm{CO}_{2}\right)$ dan polutan $\mathrm{NO}_{x}{ }^{2]}$.

\section{METODOLOGI}

Tahapan penelitian dimulai dengan penyiapan sampel bahan bakar solar murni (B0) dan Biodiesel murni (100) yang kemudian dibuat campuran B10, B20, B30, dan B50 untuk dijadikan obyek pengujian (uji properties, kinerja mesin dan emisi), seperti ditampilkan dalam gambar 1

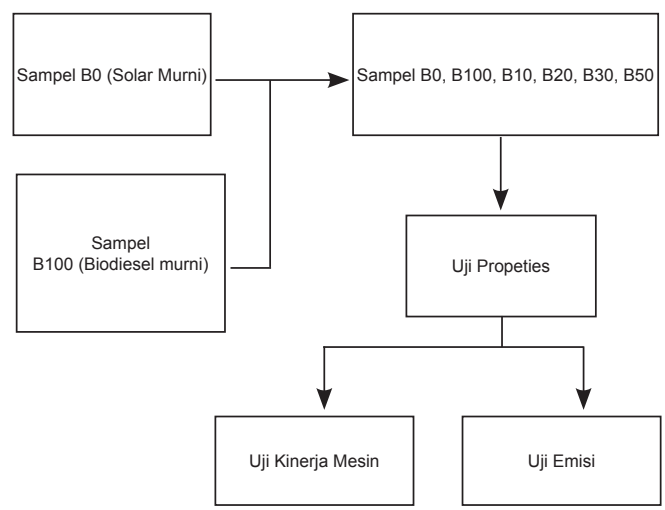

Gambar 1. Metodologi Pengujian

\subsection{Sampel Bahan Bakar}

Sampel bahan bakar solar murni ditentukan yaitu solar yang dambil langsung dari kilang minyak balongan milik Pertamina. Alasan penentuan solar dari Pertamina ini adalah solar masih murni dan diasumsikan belum terjadi perubahan spesifikasi dalam tahap distribusi. Sedangkan sampel biodiesel murni digunakan biodiesel hasil produksi proses pengolahan biodiesel Balai Rekayasa Desain dan Sistem Teknologi (BRDST-BPPT) yang berlokasi di kawasan PUSPIPTEK Serpong. Spesifikasi dari kedua sampel tersebut telah memenuhi standard yang ditentukan (SNI) seperti ditampilkan dalam Tabel 1.

Tabel 1. Spesifikasi B0 dan B100

\begin{tabular}{|c|c|c|c|c|}
\hline No & Parameter & Unit & $B(0)$ & B100 \\
\hline 1 & Density at $40^{\circ} \mathrm{C}$ & $\mathrm{kg} / \mathrm{m}^{3}$ & $\begin{array}{l}851 \\
(15 \\
\left.{ }^{\circ} \mathrm{C}\right)\end{array}$ & 859,0 \\
\hline 2 & $\begin{array}{l}\text { Kinematic } \\
\text { viscosity (40 } \\
\left.{ }^{\circ} \mathrm{C}\right)\end{array}$ & $\mathrm{Mm}^{2} / \mathrm{s}$ (cSt) & 5,733 & 4,448 \\
\hline 3 & Cetane number & & & \\
\hline 4 & Flash point & ${ }^{\circ} \mathrm{C}$ & 101 & 185 \\
\hline 5 & Cloud point & ${ }^{\circ} \mathrm{C}$ & 18 & 16 \\
\hline 6 & $\begin{array}{l}\text { Copper strip } \\
\text { corrosion }\end{array}$ & \begin{tabular}{|l|} 
Rating \\
$(3$ hours at \\
$\left.50^{\circ} \mathrm{C}\right)$ \\
\end{tabular} & No. 1 & No. 1 \\
\hline 7 & $\begin{array}{l}\text { Carbon residue } \\
\text { - in undistilled } \\
\text { sample, or - in } \\
10 \% \text { distillation } \\
\text { residue }\end{array}$ & $\begin{array}{l}\%(\mathrm{~m} / \mathrm{m}) \\
\%(\mathrm{~m} / \mathrm{m})\end{array}$ & 0,02 & $\begin{array}{l}0,02 \\
0,30\end{array}$ \\
\hline 8 & $\begin{array}{l}\text { Water and } \\
\text { sediment }\end{array}$ & $\%$-vol. & 0.05 & 0,020 \\
\hline 9 & \begin{tabular}{|l|}
$90 \%(\mathrm{v} / \mathrm{v})$ \\
recovered \\
at distillation \\
temperature
\end{tabular} & ${ }^{\circ} \mathrm{C}$ & 379 & 344 \\
\hline 10 & \begin{tabular}{|l|} 
Ash content \\
(sulfated ash)
\end{tabular} & $\%(\mathrm{~m} / \mathrm{m})$ & \begin{tabular}{|l|l|}
$<$ \\
0,01 \\
\end{tabular} & nil \\
\hline 11 & Sulfur content & $\begin{array}{l}\mathrm{ppm}-\mathrm{m} \\
(\mathrm{mg} / \mathrm{kg})\end{array}$ & 222 & $<3$ \\
\hline 12 & \begin{tabular}{|l|} 
Phosphorous \\
content
\end{tabular} & $\begin{array}{l}\text { ppm-m } \\
(\mathrm{mg} / \mathrm{kg})\end{array}$ & - & 4,960 \\
\hline 13 & Acid number & $\mathrm{mg}-\mathrm{KOH} / \mathrm{g}$ & 0,18 & 0,504 \\
\hline 14 & Free glycerol & $\%(\mathrm{~m} / \mathrm{m})$ & - & 0,0052 \\
\hline 15 & Total glycerol & $\%(\mathrm{~m} / \mathrm{m})$ & - & 0,23967 \\
\hline 16 & Ester content & $\%(\mathrm{~m} / \mathrm{m})$ & - & 99,158 \\
\hline 17 & lodine number & $\begin{array}{l}\%(\mathrm{~m} / \mathrm{m}) \\
(\mathrm{g}-12 / 100 \mathrm{~g})\end{array}$ & - & 58,550 \\
\hline 18 & Halphen test & & - & negative \\
\hline
\end{tabular}




\subsection{Pengujian Mesin}

Pengujian kinerja dan emisi gas buang dari mesin dilakukan dengan menggunakan chassis dynamometer di Laboratorium Balai Termodinamika, Mesin dan Propulsi (BTMPBPPT).

Spesifikasi kendaraan yang diiuji:

- Kendaraan penumpang tahun 2004;

- Direct injection;

- Transmisi otomatis;

- Kapasitas mesin diesel 2500 cc

Chassis dynamometer terdiri dari sepasang drum dengan diameter 48 inchi. Roda bagian belakang dari kendaraan ditempatkan pada drum tersebut (seperti terlihat pada gambar 2). Drum ini dihubungkan dengan sebuah motor arus searah dengan spesifikasi sebagai berikut:

- Kecepatan maksimum 200 km/jam

- Daya maksimum $150 \mathrm{~kW}$

- Inertia dapat diuji: $454-2722 \mathrm{~kg}$

- Suhu ruangan pengujian: $5^{\circ}-40^{\circ} \mathrm{C}$

\subsection{Analisa Emisi}

Sistem analisa dari emisi CVS (Constant Volume Sampling) terdiri dari lima bagian utama yaitu handling unit (sistem pengelola), bag (kantong), partikel dan hydrocarbon sampling system dan penganalisa emisi.

Fungsi dari sistem pengelola adalah untuk mengontrol sirkulasi gas keluaran (exhaust gas) dari kendaraan. Emisi dari CVS dikumpulkan dalam kantong. Sistem penyampelan partikel dan hydrocarbon hanya digunakan untuk pengujian kendaraaan bermesin diesel. Sistem analisa emisi terdiri dari penganalisa gas (gas analyzer) yang berfungsi untuk menganalisa emisi gas buang dari kantong atau kondisi transient dan menimbang partikel.

Spesifikasi alat penganalisa gas adalah sebagai berikut:
- Total Hydrocarbon Analyzer

Detector: heated flame ionization

Accuracy and repeatability: $+/-1 \%$

Measurement range: 0-4, 0-10,

0-100,0-400, 0-1000, 0-4000, 0-10000

ppm

Response time: $2 \mathrm{~s}$ at $2 \mathrm{~L} / \mathrm{min}$ flow rate

Ambient temperature: $5-40^{\circ} \mathrm{C}$

Relative humidity: maximum $95 \%$

- $\quad \mathrm{NO}_{\mathrm{x}}$ analyzer

Detector. Chemiluminescent

Accuracy and repeatability:+/- 1\%

Measurement range: 0-4, 0-10, 0-100, 0-400, 0-1000, 0-4000, 0-10000 ppm

Respond time: $1.5 \mathrm{~s}$ at $2 \mathrm{~L} / \mathrm{min}$ flow rate

\section{- $\quad$ CO analyzer}

Detector : non dispersive infra-red Accuracy and repeatability: $+/-1 \%$ Measurement range: 0-100, 500,1000 ppm, $1 \%, 5 \%, 10 \%$

Respond time: $15 \mathrm{~s}$ at $1 \mathrm{~L} / \mathrm{min}$ flow rate

Ambient temperature: $5-30^{\circ} \mathrm{C}$

\section{- $\quad$ Particulate weighing}

Maximum load: $5000 \mathrm{mg}$

Readability: $0.001 \mathrm{mg}$

Time for stabilization: $10 \mathrm{~s}$

Filter used: PALLFLEX-70mm

Tata letak dari peralatan uji ditampilkan dalam gambar 2 .



Gambar2. Tata Letak Peralatan Uji 


\section{HASIL DAN DISKUSI}

Pengujian emisi untuk semua sampel diuji dengan standar pengukuran ECE R83 (EURO 2) seperti terlihat pada gambar 3. Penggunaan bahan bakar diukur dengan metoda pengujian ECE No.84 dan kinerja mesin diuji dengan metoda 80/1269 EEC.

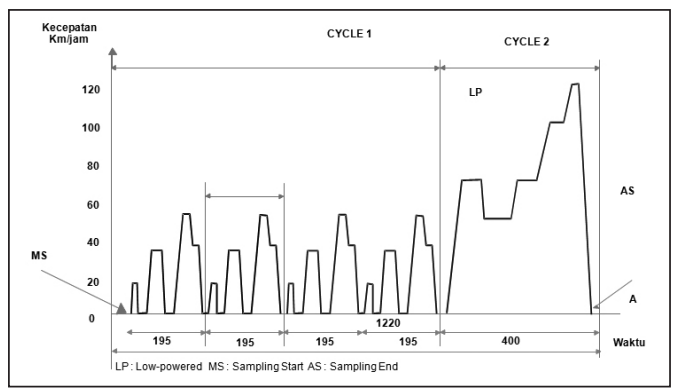

\subsection{Kinerja Mesin}

Hasil pengukuran kinerja mesin digambarkan dalam bentuk grafis seperti terlihat pada gambar 4 dan 5. Gambar tersebut memperlihatkan torsi dan daya mesin versus kecepatan mesin sebagai fungsi dari beberapa komposisi campuran biodiesel (B0, B10, B20, B30, B50 dan B100).

Pada gambar 4 terlihat bahwa daya puncak dicapai pada kecepatan yang sama yaitu $70 \mathrm{~km} / \mathrm{jam}$. Daya paling kecil dihasilkan oleh mesin yang menggunakan B100 (56 $\mathrm{kW})$.

Hasil pengujian memperlihatkan bahwa daya yang dibangkitkan oleh B100 lebih rendah dari pada daya yang dihasilkan oleh B0. Hal ini disebabkan oleh nilai kalori dari biodiesel murni lebih rendah sekitar $10 \%$ dari minyak solar murni (B0).

Gambar 5 memperlihatkan bahwa torsi maksimum tercapai pada kecepatan 30-40 $\mathrm{km} / \mathrm{jam}$ untuk semua jenis bahan bakar. Torsi yang paling rendah adalah untuk biodiesel murni (B100).

Dari gambar 4 dan 5 terlihat bahwa campuran terbaik adalah untuk $20 \%$ biodiesel (B20) dimana pada kecepatan $70 \mathrm{~km} / \mathrm{jam}$ didapat daya dan torsi tertinggi.

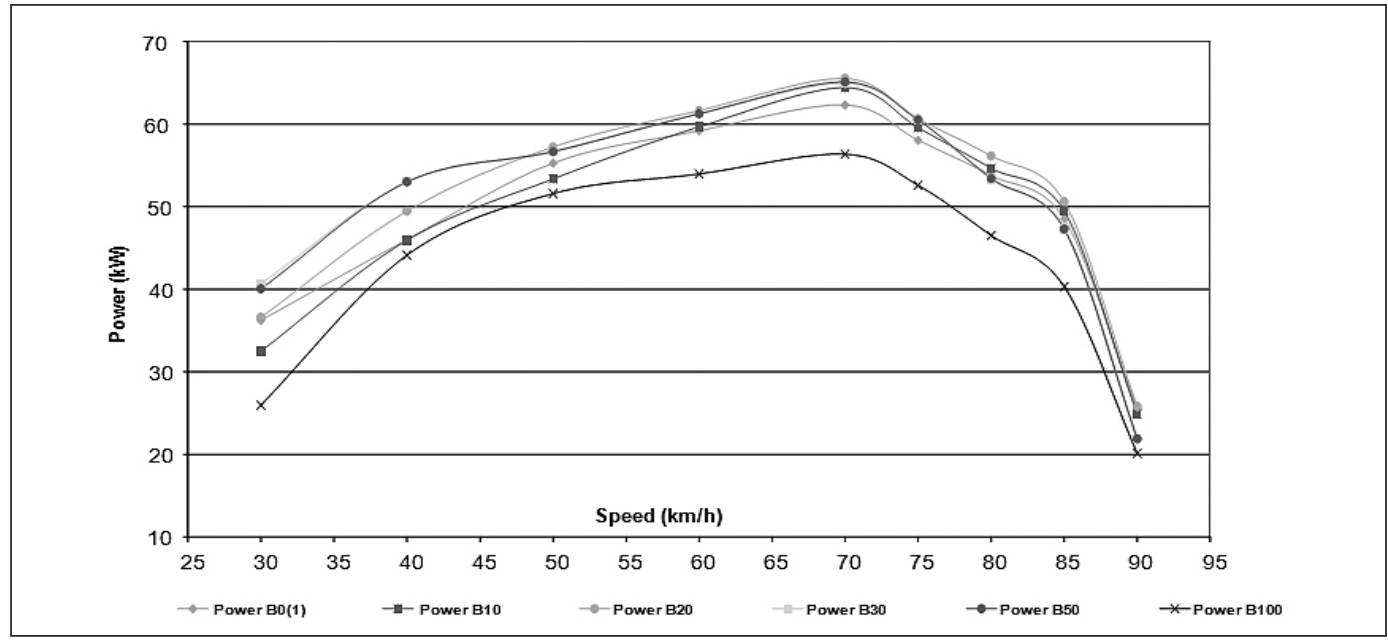

Gambar 4. Daya vs Kecepatan Mesin

\subsection{Pengaruh Biodiesel Terhadap Emisi dan Konsumsi Bahan Bakar}

Pengaruh komposisi biodiesel untuk pengurangan emisi gas buang ditunjukkan pada gambar 6. Dimana terlihat emisi gas buang turun secara linier dengan penambahan campuran biodiesel. Emisi partikel berkurang dengan tajam untuk B10, sedangkan emisi $\mathrm{HC}$ mulai berkurang pada campuran biodiesel 20\% (B20).

Pengaruh dari sulphur didalam solar 
pada emisi partikel telah diteliti oleh Merkisz 3] dimana hasilnya adalah partikel tertinggi terjadi untuk bahan bakar yang mengandung sulphur tertinggi. Untuk bahan bakar yang mengandung sulphur rendah (350-50 ppm) menghasilkan partikel (PM) yang sama. Tetapi untuk bahan bakar yang mengandung sulphur lebih tinggi (2000 ppm) akan menghasilkan PM 20\% lebih tinggi dari pada solar yang mengandung sulphur rendah.

Emisi $\mathrm{CO}$ dan $\mathrm{NO}_{x}$ juga berkurang walaupun tidak setajam penurunan emisi partikel dan HC. Hasil pengukuran Emisi $\mathrm{NO}_{x}$ untuk campuran biodiesel yang tinggi terlihat rendah, hasil ini berlawanan dengan hasil penelitian yang telah dilakukan untuk biodiesel berbahan baku bukan sawit.

$\mathrm{Hal}$ ini disebabkan karena pembentukan $\mathrm{NO}_{x}$ tergantung dari suhu pembakaran dan kandungan oksigen didalam campuran pembakaran. Karena bahan bakar campuran biodiesel mempunyai kemampuan pembakaran yang lebih cepat, akan menaikkan suhu ruang bakar dan tekanan, yang kemudian meningkatkan pembentukan $\mathrm{NO}_{x}$.

Hampir pada semua rujukan menyatakan bahwa mesin yang menggunakan bahan bakar biodiesel menghasilkan peningkatan sedikit emisi $\mathrm{NO}_{x}{ }^{4]}$.

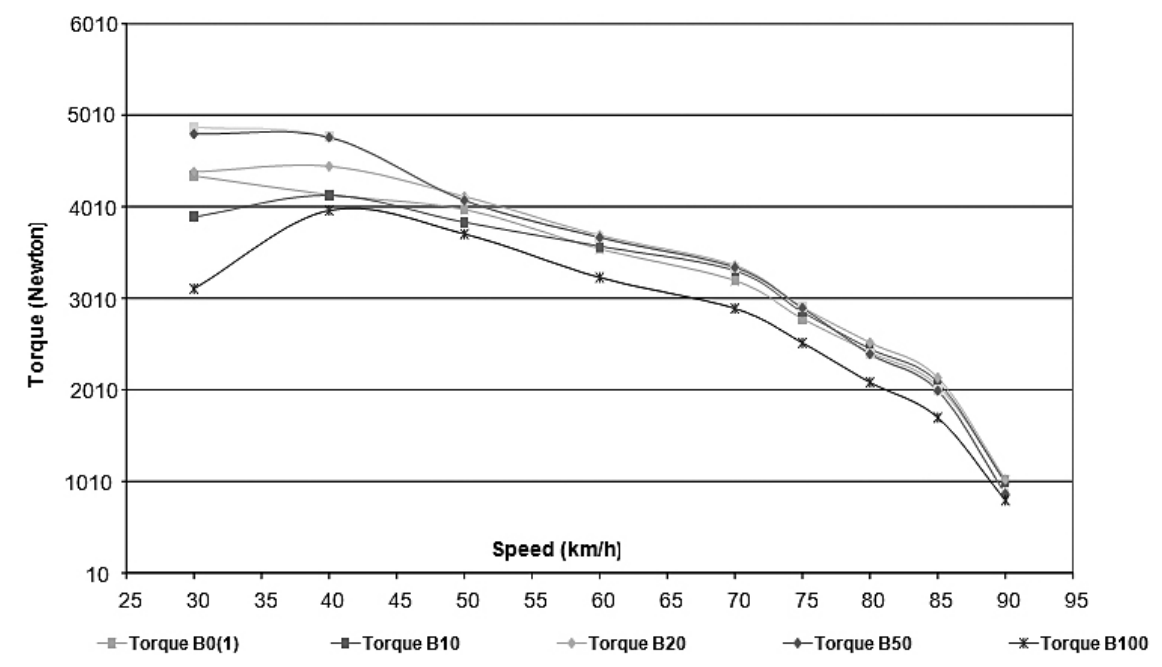

Gambar 5. Torsi vs Kecepatan Mesin

Gambar 7 memperlihatkan hasil pengukuran konsumsi bahan bakar terhadap komposisi campuran biodiesel.

Konsumsi bahan bakar untuk B100 $(0,69 \mathrm{~L} / 10 \mathrm{~km})$ adalah lebih tinggi dari pada konsumsi bahan bakar B0 yaitu sebesar $1,03 \mathrm{~L} / 10 \mathrm{~km}$.

Walaupun emisi $\mathrm{CO}$ dan $\mathrm{HC}$ dari $\mathrm{BO}$ lebih tinggi dari pada B100, B0 melepaskan emisi $\mathrm{CO}_{2}$ lebih rendah dari pada $\mathrm{B} 100$ yang mengakibatkan efek yang signifikan dalam mengurangi konsumsi bahan bakar.

Dari kurva gambar 7 terlihat bahwa pengurangan konsumsi bahan bakar tergantung dari komposisi campuran biodiesel. B10, B20, B30, B50 dan B100 yaitu $6 \%, 9 \%, 16 \%, 22 \%$ dan $33 \%$.

Hasil ini menunjukkan hubungan yang jelas antara viskositas bahan bakar dengan atomisasi bahan bakar. Viskositas bahan bakar yang tinggi cenderung mengurangi kualitas dari atomisasi bahan bakar yang berakibat kepada emisi dan konsumsi bahan bakar.

Sifat kimiawi dan fisika dari bahan bakar seperti angka cetane akan menentukan 


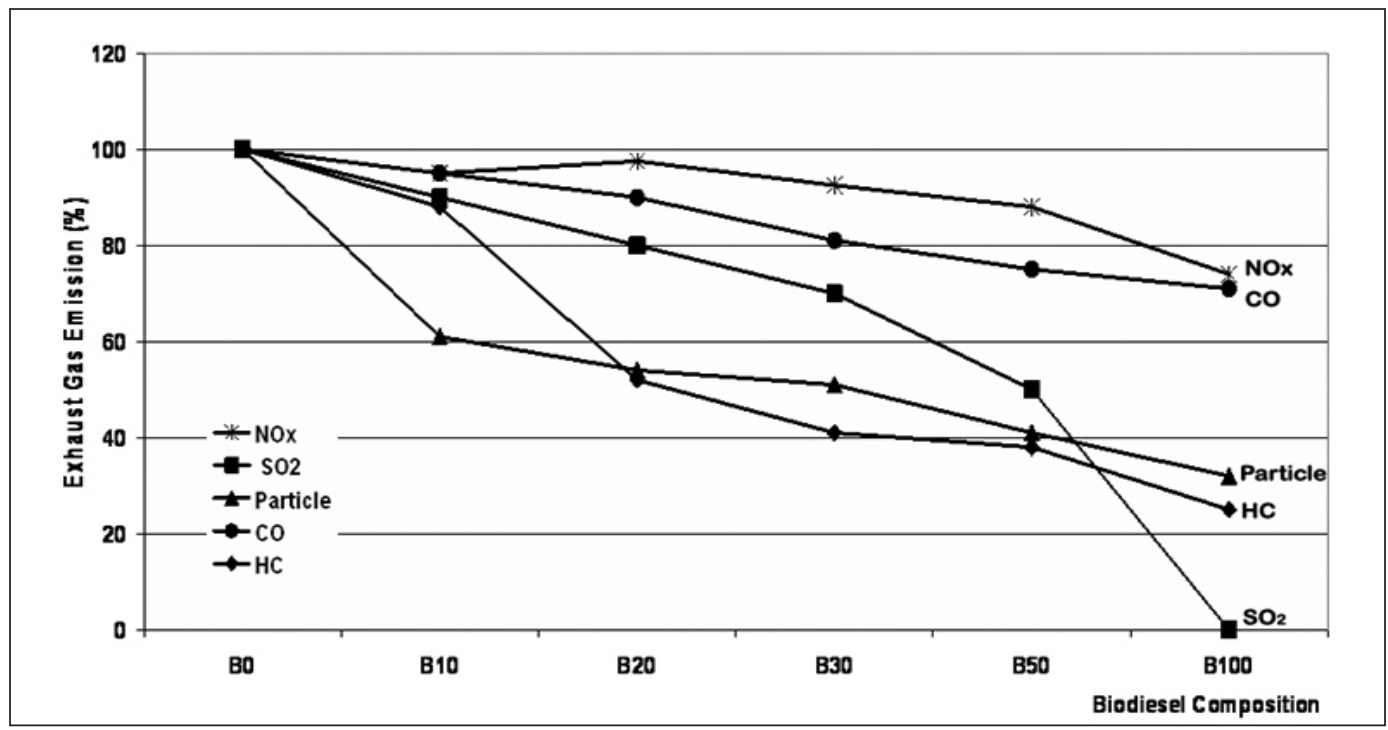

Gambar 6. Pengaruh Campuran Biodiesel Terhadap Emisi

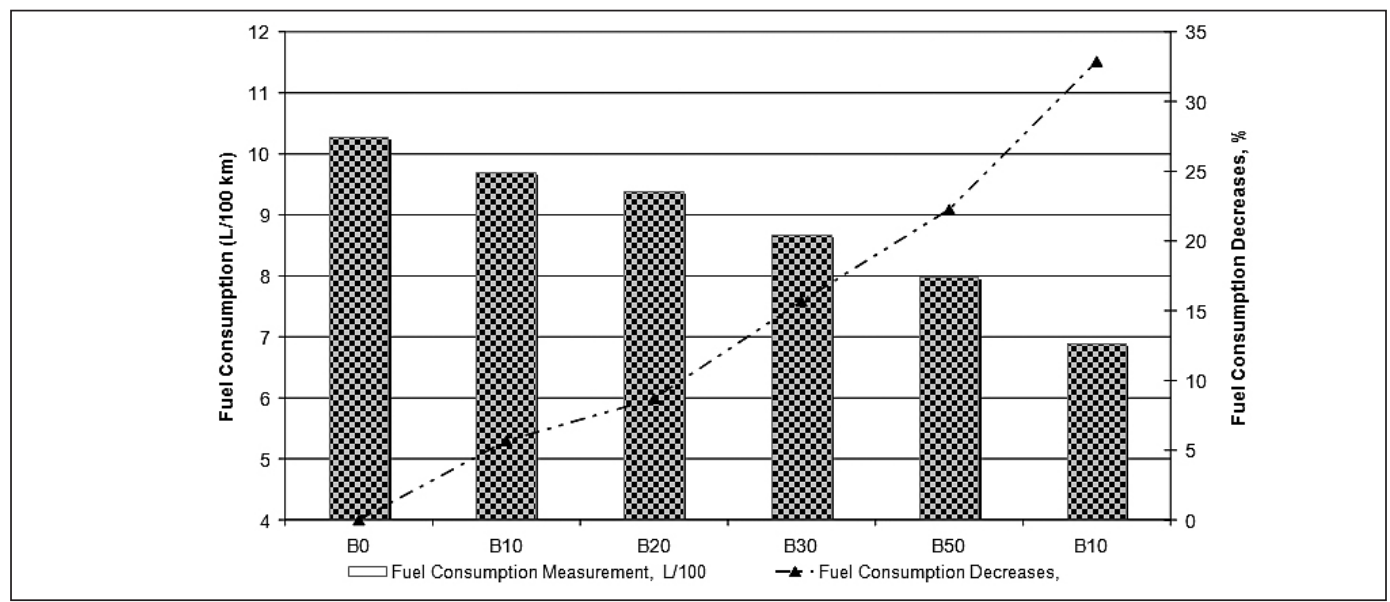

Gambar 7. Konsumsi Bahan Bakar Terhadap Komposisi Biodisel

kandungan emisi gas buang $\mathrm{NO}_{x}{ }^{5,6]}$. Secara umum dapat dikatakan bahwa pembentukan emisi $\mathrm{NO}_{x}$ sangat kompleks karena tergantung kepada bahan bakar, teknologi mesin dan faktor siklus pengujian

\section{KESIMPULAN DAN SARAN}

\subsection{Kesimpulan}

Hasil pengujian membuktikan bahwa penambahan biodiesel sampai dengan $20 \%$ kedalam solar dapat meningkatkan kinerja mesin. Daya dan torsi tertinggi dihasilkan pada kecepatan $70 \mathrm{~km} / \mathrm{jam}$, akan tetapi penambahan komposisi bidiesel lebih tinggi mengakibatkan penurunan kinerja mesin.

Emisi $\mathrm{SO}_{2}$, partikel, $\mathrm{CO}$ dan $\mathrm{NO}_{\mathrm{x}}$. menurun secara konsisten dengan peningkatan kandungan biodiesel dalam campuran bahan bakar. Akan tetapi karakteristiknya bervariasi tergantung dari jenis emisinya. Penurunan kadar emisi paling signifikan dengan digunakannya biodiesel terjadi pada emisi $\mathrm{SO}_{2}$ dan PM. 


\subsection{Saran}

Dalam mensukseskan penerapan biodiesel sebagai bahan bakar untuk mensubtitusi minyak, perlu juga dilakukan penelitian tentang faktor-faktor sosial ekonomi, seperti penerimaan masyarakat, efek terhadap pertumbuhan ekonomi, penurunan angka kemiskinan dan pembukaan kesempatan kerja sesuai dengan strategi pembangunan nasional yang dicanangkan oleh Bapak Presiden RI dan dikenal dengan istilah "Triple Track Strategy"

\section{DAFTAR PUSTAKA}

1. Moreno, F., M. Munoz and J. MoreaRoy. Sunflower Methyl Ester as a Fuel for Automobile Diesel Engines. In Transaction of the ASAE 42(5):11811185. 1999.

2. Wirawan, S.S. Tambunan, A.H. Djamin, M. and Nabetani, H. The Effect of Palm Biodiesel Fuel on the Performance and Emission of the Automotive Diesel Engine. Agricultural Engineering International: the CIGR Ejournal. Manuscript EE 07 005. Vol. X. April. 2008.
3. Merkisz, J., M. Kozak, P. Bielaczyc, A. Szczotka. An Investigation of Influence of Diesel Fuel Sulphur Content on Particulates Emissions From Direct Injection Common Rail Diesel Vehicle. Journal of KONES Internal Combustion Engines, No. 3 - 4 ISSN 1231 - 4005. 2002.

4. Mittelbach M, Remschmidt C. Biodiesel, The Comprehensive Handbook. $1^{\text {st }}$ ed. Graz Austria: Martin Mittelbach (Publisher); 2004.

5. Sharp, C. Emission with ethyl and methyl esters of biodiesel. In Commercialization of Bodies: Environmental and Health Benefits. Moscow. Idaho: National Institute for Advanced Transp. Tech. University of Idaho. 1996.

6. Peterson, C. L., J. S. Taberski, J.C. Thompson and C.L. Chase. 2000. The Effect of Biodiesel Feedstock on Regulated Emission in Chassis Dynamometer Test of a Pickup Truck. In Transaction of the ASAE 43(6):13711381 